\title{
Pisacano Leadership Foundation Names 2011 Pisacano Scholars
}

\section{Jane Ireland}

The Pisacano Leadership Foundation, the philanthropic arm of the American Board of Family Medicine, recently selected its 2011 Pisacano Scholars. These five medical students follow in the footsteps of 80 scholar alumni who are practicing physicians and 16 current scholars who are enrolled in family medicine residency programs across the country. The Pisacano Leadership Foundation was created in 1990 by the American Board of Family Medicine in tribute to its founder and first executive director, Nicholas J. Pisacano, MD (1924-1990). Each Pisacano Scholar has demonstrated the highest level of leadership, academic achievement, communication skills, community service, character, and integrity.

Rebecca Mitchell Coelius, a 2011 Pisacano Scholar, is a fourth-year medical student at the Uni-

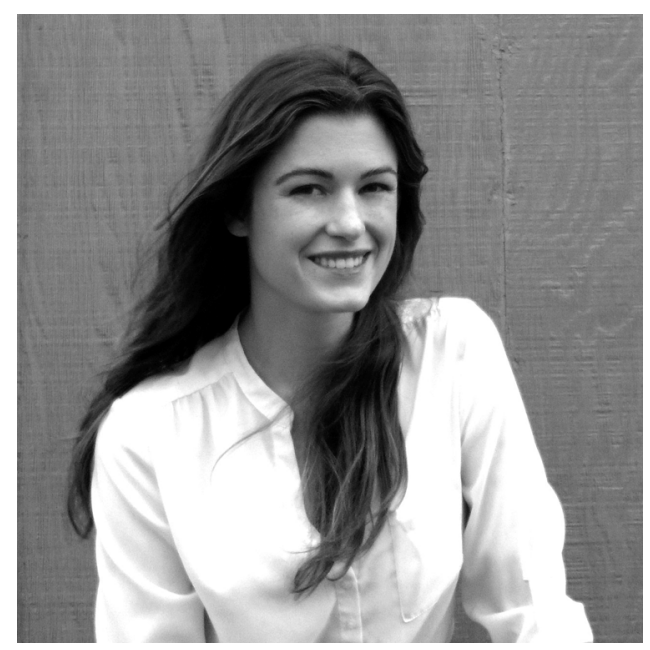

From the American Board of Family Medicine, Lexington, $\mathrm{KY}$.

Funding: none.

Conflict of interest: none declared. versity of California, San Francisco (UCSF), School of Medicine. She graduated Magna Cum Laude from the University of Minnesota-Twin Cities with a Bachelor of Arts in Biology, Society, and the Environment. Rebecca received numerous awards as an undergraduate, including the Harry Truman Scholarship for Public Service, the USA Today All-USA Academic First Team Award, the Glamour Top Ten College Women Award, and the University of Minnesota AI Johnson Scholarship for Public Service, which supports maternal health research in Egypt.

Rebecca volunteered profusely as an undergraduate, including a summer at an orphanage in Kenya. She was inspired by community efforts toward seemingly intractable development challenges and founded the international nonprofit SpanAfrica, which has partnered with more than 50 organizations across Kenya, Zambia, and Ghana in support of local approaches to health, microfinance, sustainable agriculture, and education. She remains directly involved and is a board member and the director of volunteer operations. After completing her undergraduate work, Rebecca was a Fulbright Scholar in India. She traveled across the subcontinent researching how US humanitarian aid policy was impacting women's reproductive health and HIV/AIDS projects at the local level.

While at UCSF School of Medicine, Rebecca has been awarded the Dean's Research Fellowship for research on patient attitudes about the potential of computer-assisted health care to improve quality in primary and acute care clinics. She remains dedicated to exploring how technology can enhance patient care, especially within the areas of preventative medicine, health education, and the management of chronic disease.

Rebecca also has served as the American Medical Student Association's National PharmFree Director of Access to Medicines, and she was one of the leaders in a national campaign to consider access and affordability in federal patent policy for biological medicines. She is involved with Universities 
Allied for Essential Medicine in support of access to medicines and awareness around conflicts of interest between the pharmaceutical and health industry. Rebecca has been a student representative on the American College of Physician's California Health and Public Policy Committee, a student coordinator for the UCSF Bioethics and Health Policy Electives, and a representative to the school of medicine student government. She was an editor of the web-based Global Pulse fournal. This year Rebecca is working with the San Francisco General Hospital Center for Excellence in Primary Care to support the transformation of a local community health center into a model for innovation in primary care provision.

Rebecca plans to practice full-spectrum family medicine. She looks forward to being involved in innovations in the organization, delivery, and financing of primary care.

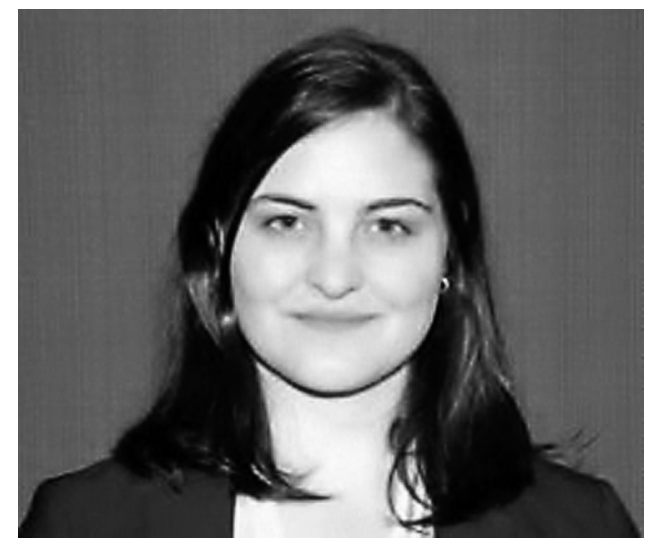

Alexandra Hunt, a 2011 Pisacano Scholar, is a fourth-year medical student at the University of Washington (UW) School of Medicine. She graduated with honors from the University of California Santa Cruz with a Bachelor's degree in Art. Alexandra was team captain of the University of California Santa Cruz women's soccer team and was named NCAA All-Western Region Women's Soccer Player of the Year during her junior year. That same year, the team also advanced to the NCAA National Championship for the first time in the team's history and then again the following year.

Before entering medical school, Alexandra worked for a couple of years as an office assistant and facilities coordinator for a church in Santa
Cruz. During this time she coached women's and girls' soccer teams in the area. She later worked for 1 year as a health educator and volunteer assistant at a rural health clinic in El Salvador. Alexandra points to this experience as a turning point in her life, when she decided to actively pursue her lifelong dream of becoming a physician. After her time in El Salvador, while pursuing medical school prerequisite courses, Alexandra worked as a comprehensive perinatal health worker for the Comprehensive Perinatal Support Program of California. During this time, she volunteered with the burn intensive care unit of a local hospital - an experience that Alexandra describes as crystallizing her commitment to community education and burn prevention that can be effectively conducted as a family physician and community leader.

Alexandra is a board member and volunteer for the Children's Health International Medical Project of Seattle. She served as a translator and cultural ambassador for June medical team trips to rural El Salvador on three separate occasions. She is also the coordinator and a volunteer with the Perinatal Care Project. This project pairs a medical student with a young, single woman who is a participant in the program. The student attends prenatal appointments, labor and delivery, and postpartum checkups alongside the participant. Alexandra has been involved in and a leader with UW's Family Medicine Interest Group for the last 2 years, helping organize and implement multiple Family Medicine Interest Group events.

Alexandra has continued her community service throughout medical school. She has volunteered with the free sports medicine clinic, the Latina Health Fair, the Aloha Inn Clinic, and currently with the Dermatology Clinic for Homeless Men and Women and the Casa Latina Clinic. Alexandra is currently a member of the Latino Medical Student Association and UW's Global Health Pathway and Hispanic Health Pathway. She is the recent recipient of the SPARX/CHAP Exceptional Participation Award, which is given to those students who demonstrate a major commitment to the program through their volunteer service.

Alexandra remains passionate about pursuing a career in family medicine within the setting of a rural-designated area in need of primary care providers, where she can come alongside the community to empower its members to reach their health advancement goals. 


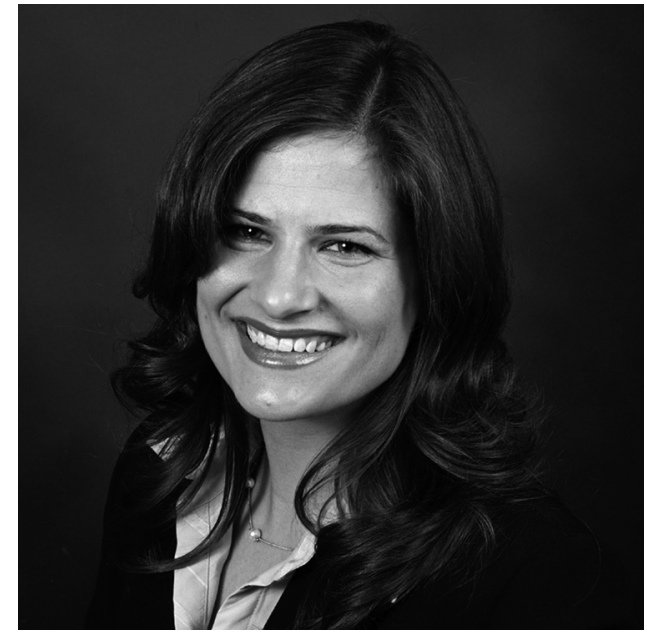

Jessica Johnson, a 2011 Pisacano Scholar, is a fourth-year medical student at the University of Connecticut (UConn) School of Medicine, where she is also currently completing her Masters in Public Health. She graduated Summa Cum Laude from the University of Pennsylvania with a Bachelor of Arts in French, where she was also a Dean's List recipient and a member of Phi Sigma Pi National Honor Fraternity.

Before medical school, Jessica worked for a few years as a risk analyst for an insurance broker and a risk advising company. Though she found this to be a valuable experience, Jessica missed working with people and communities in a meaningful way, and it was during this time that she rekindled an earlier interest in medicine. She then worked as an emergency medical technician for 2 years before entering medical school. During her first year of medical school, Jessica was accepted into the Urban Service Track (UST), a university-wide interdisciplinary program in medicine, nursing, pharmacy, and dentistry that prepares students for service to urban vulnerable populations. Jessica was among the first to receive the UST Leadership Award, given for leadership and community service within the UST Program. She was recently asked to serve as a student mentor in the program.

In the summer and fall after her first year of medical school, Jessica co-organized the annual UConn Migrant Farm Workers Clinic. The mobile free clinic visits farm worker barracks across the state to provide primary care and referrals to community health centers when needed. She worked with two other medical students and staff to coordinate the program. During the season they served more than 1250 patients. Also, during her first year of medical school, Jessica restarted the school's Family Medicine Interest Group, which is now thriving. Jessica has volunteered with South Park Inn Clinic, a student-run free clinic, since beginning medical school, and she has sat on the board for 3 years. She was inducted into the Gold Humanism Honor Society in 2010. Last year, Jessica spent a year as a health policy intern with the Primary Care Coalition of Connecticut while completing her MPH coursework. She assisted in facilitating strategic planning for a coalition of 17 primary care provider groups and relevant stakeholders and provided policy analysis and testimony during the legislative session. Jessica also has served as the student member on the Board of the Connecticut Academy of Family Physicians, FMIG Regional Coordinator, Student Delegate to the American Academy of Family Physicians Congress of Delegates, and student representative to the Primary Care Coalition of Connecticut. Most recently, Jessica was nominated as the Student Member of the Board of Directors of the American Academy of Family Physicians.

In her future career as a family physician, Jessica looks forward to providing full-spectrum care in diverse communities and to implementing creative approaches to health promotion and social justice. She plans to combine her clinical practice with teaching medical students and residents and with continued advocacy for patients, communities, and system-wide health care reform.

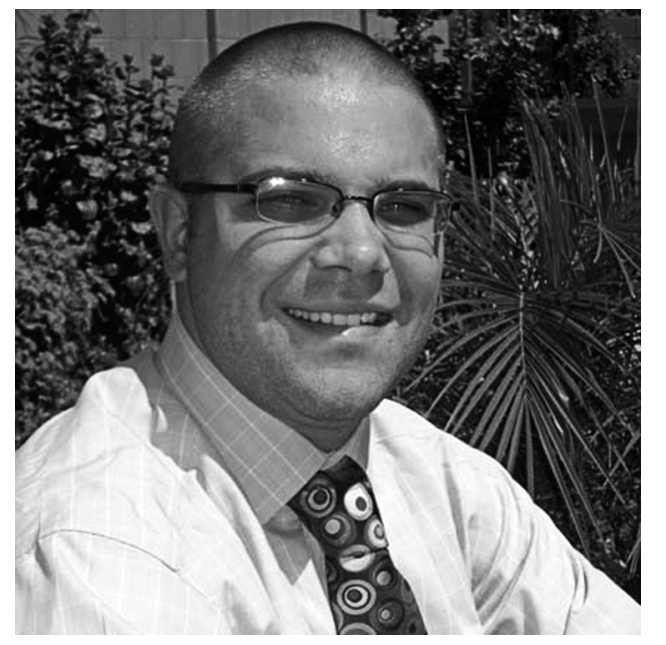


Nathan Kittle, a 2011 Pisacano Scholar, is a fourth-year medical student at Loyola University Chicago Stritch School of Medicine, where he is also earning his master's in bioethics and health policy. He graduated from Creighton University with a Bachelor of Arts in Anthropology. Nathan has been actively involved in community service both nationally and locally. During college, he participated in and led numerous service trips to poverty-stricken areas in the United States. Nathan also served as a resident advisor his last 2 years at Creighton and as an intramural sports supervisor and referee for 3 years.

After graduating from Creighton, Nathan spent a year as a full-time volunteer with Amate House, a young-adult volunteer program inspired by the social mission of the Catholic Church, which is dedicated to service and committed to building a more just and loving society. With the Amate House program, Nathan worked as a case manager at the Marjorie Kovler Center for the Treatment of Survivors of Torture-an experience that he says taught him lessons he could not have learned any other way and that still inspire his current life and will continue to shape his future.

As a medical student, Nathan has continued his academic achievement and commitment to service. He has received a number of scholarships, including an Albert Schweitzer Fellowship. In addition, Nathan was chosen for a Dean's Development Award to complete his master's degree at Loyola. He was also recently selected as one of only a few students to represent the Loyola School of Medicine in a leadership development program put in place to help discover ways the health system can better serve patients, improve clinical service, and enhance medical education.

As a Loyola Global Health Fellow, Nathan recently began a fellowship in Palacios, Bolivia. This 1 -year fellowship is part of a 4-year longitudinal Global Health Scholars program at Loyola and will focus on health care delivery in resource-poor settings. He will work closely with the local Bolivian staff and community health workers to develop community-based projects for the surrounding communities of Palacios.

Nathan is a member of the Center for Service and Global Health (CSGH) Student Advisory Board. The goal of the CSGH is to bring Loyola's many service projects and international projects under one umbrella, allowing students to collabo- rate with each other and faculty to expand their outreach. The most important activity Nathan led as part of the CSGH was organizing Loyola's first annual "Mission in Action: Loyola Day of Service." This project introduces students to the community they will call home for the next 4 years and gives them the opportunity to volunteer in different areas, ranging from collecting trash on a local prairie path to working with the local Fine Arts Association.

In his future career as a family physician, Nathan hopes to continue working among underserved communities both locally and abroad. He specifically has a heart for working with refugee communities and hopes to work to improve their care and bring attention to their struggles by remaining involved in academic medicine and policy work.

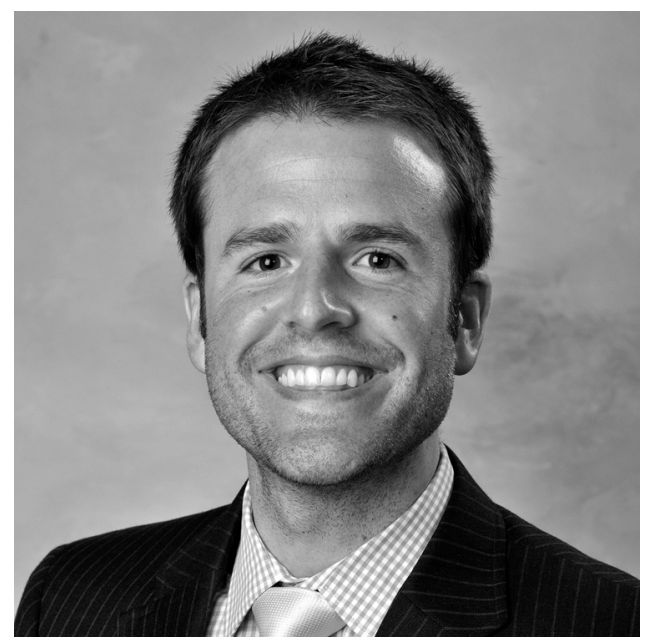

Benjamin Preyss, a 2011 Pisacano Scholar, is a fourth-year medical student at the University of Illinois at Chicago (UIC) College of Medicine, where he is pursuing a joint MD/MBA degree. $\mathrm{He}$ graduated with honors from The University of Chicago with a Bachelor of Arts in Human Development. He was a multiple Dean's List recipient and was awarded Distinct Honors in Human Development by the University of Chicago Committee for Human Development for the presentation of his senior thesis. Benjamin was also captain of the men's varsity soccer team and received many accolades, including First Team All-American. In addition, Benjamin worked as campus manager for Teach for America during the last 2 years of college 
and traveled to indigenous villages in the Oaxaca Valley in Mexico as a student leader on multiple short-term medical mission trips.

Before medical school, Benjamin worked as a research consultant with one of the nation's leading research and consulting firms, where he addressed the organization and financing of health care for vulnerable populations. It was through this experience that Benjamin began to understand how he could impact health services for medically vulnerable populations and stirred his desire to become a physician leader.

Since entering medical school, Benjamin has continued his community service and has received a number of awards, including the Albert Schweitzer Fellowship. As a Schweitzer Fellow, he worked to create and implement a health and wellness curriculum for Urban Initiatives, an extracurricular program working with more than 500 elementary students in some of Chicago's most underserved communities. Benjamin also recently began serving as a principal mentor to formerly homeless adolescents and young adults as part of a mentoring pilot program with Schweitzer Fellows for Life. During this time, he will offer advice and life skills to his mentees as they prepare to leave transitional housing and ultimately live independently.

Benjamin is also a member of UIC's Urban Medicine program, a unique 4-year medical school curriculum preparing physician-leaders to serve urban communities. Most recently, he was inducted into UIC's chapter of the Gold Humanism Honor Society, a national organization recognizing outstanding humanistic character and performance by medical students.

While completing his MBA curriculum, Benjamin was awarded the Grand Prize at UIC's campus-wide business competition for leading a management team in the creation of a business plan to establish a new faith-based community health center in Chicago's Humboldt Park community. In his role as Executive Director, Benjamin oversaw all the original operational and strategic planning as well as seed-stage fundraising.

Benjamin plans to continue this type of work after residency. He envisions combining his skills as an administrative leader and a family physician to provide accessible, high-quality, and comprehensive care to those communities and patients who remain most in need. 